\title{
Eye Fixations and Memory for Emotional Events
}

\author{
Sven-Åke Christianson \\ University of Stockholm \\ Stockholm, Sweden \\ Elizabeth F. Loftus, Hunter Hoffman, and Geoffrey R. Loftus \\ University of Washington
}

\begin{abstract}
Subjects watched either an emotional, neutral, or unusual sequence of slides containing 1 critical slide in the middle. Experiments 1 and 2 allowed only a single eye fixation on the critical slide by presenting it for $180 \mathrm{~ms}$ (Experiment 1) or $150 \mathrm{~ms}$ (Experiment 2). Despite this constraint, memory for a central detail was better for the emotional condition. In Experiment 3, subjects were allowed $2.70 \mathrm{~s}$ to view the critical slide while their eye movements were monitored. When subjects who had devoted the same number of fixations were compared, memory for the central detail of the emotional slide was again better. The results suggest that enhanced memory for detail information of an emotional event does not occur solely because more attention is devoted to the emotional information.
\end{abstract}

The purpose of this series of studies was to examine the role of attention and focusing patterns in memory for emotional versus neutral events. We use the term emotional events in this paper to refer to scenes that have unpleasant visual features (e.g., blood) and that have the potential to evoke negative emotional feelings in the viewer. How well are details from such emotional events remembered compared with neutral counterparts?

A number of studies have found that central detail information was better retained, while peripheral ${ }^{\prime}$ detail information was less well retained from emotional events compared with neutral events (e.g., Christianson, 1984; Christianson \& Loftus, 1987, 1991). In the Christianson and Loftus (1991) research, for example, subjects were presented with a thematic series of slides in which the content of one critical slide in the middle of the series was varied. In a neutral condition, this critical slide showed a woman riding a bike. In an emotional condition the woman was seen lying on the ground beside her bike bleeding from a head injury. The results showed that a detail associated with the central woman (the color of the

This research was supported by Grant F. 158/88 from the Swedish Council for Research in the Humanities and Social Sciences to SvenÁke Christianson, by grants from the U.S. National Science Foundation and the National Institute of Mental Health (NIMH) to Elizabeth Loftus, and by an NIMH grant to Geoffrey R. Loftus. This research was conducted while Sven-Äke Christianson, was a visiting scholar at the Department of Psychology, University of Washington and on fellowship awards from the Fulbright Commission and from the Swedish Institute.

We would like to thank Tiffanie Kilmer, Nancy Korf, Björn Levidow, and Paul Pribach for their help with data collection and analysis. We would also like to thank Albrecht Inhoff, Stephen Lindsay, and Colin MacLeod for their comments on an earlier draft of this article.

Correspondence concerning this article should be addressed to Sven-Äke Christianson, Department of Psychology, University of Stockholm, S-106 91 Stockholm, Sweden. woman's coat) was better retained in the emotional condition than in the neutral condition and that memory for a peripheral detail (the color of a distinct car) was poorer in the emotional than in the neutral condition.

There are a number of possible explanations for the finding of enhanced memory for a central detail of an emotional event but depressed memory for a peripheral detail. One highly plausible explanation has to do with attention or attention-catching features of the emotional event. An attentional explanation would suggest that in the time allotted to view the scene, subjects are fixating on the central detail, and minimal attention is allocated to the peripheral information. This idea is in line with Easterbrook (1959), who emphasized the effects of emotion or stress on the selectivity of attention. According to Easterbrook's view, an emotional event is accompanied by attentional narrowing, which could mean that fewer details are processed. Such selectivity could be associated with improvements in memory for some central details at the expense of memory for other, more peripheral details. Thus, it may be that the only reason subjects remember central details of emotional events better is that they look at these details more than do subjects who see a neutral event.

Consistent with the idea of attentional narrowing during exposure to emotional events is research on the phenomenon of weapon focusing (see, e.g., Kramer, Buckhout, \& Eugenio, 1990; E. F. Loftus, 1979; E. F. Loftus, G. R. Loftus, \& Messo, 1987; Maass \& Kohnken, 1989). Studies on weapon focusing demonstrate that certain stressful objects, such as a gun or a knife being used in a crime, can capture people's attention and thus promote memory of the weapon, but at the expense of other details in memory.

Furthermore, perception experiments, in which subjects' eye movements have been monitored while they have been presented with complex scenes (G. R. Loftus \& Mackworth,

\footnotetext{
${ }^{1}$ The terms central and peripheral refer to both topic relevance and retinal eccentricity in the experiments to be discussed.
} 
1978), have shown that people fixate more often and for longer durations on unusual or highly informative objects. In a study by E. F. Loftus, G. R. Loftus, and Messo (1987), eye movements were monitored while subjects were presented with one of two versions of a story that begins with a customer going through a cafeteria line in a fast-food restaurant. In the weapon version, the customer points a gun at the cashier, who hands over some money. In the nonweapon version, the customer hands the cashier a check, and the cashier returns some money. Except for the gun and check episodes, the two events were identical. The results indicated that subjects fixated on the weapon more and longer than on the check. It was also found that subjects in the weapon condition had poorer memory for circumstantial details of the event, such as the appearance of the "customer." No memory measure was employed, however, on the critical central object, the weapon or the check. The common interpretation of this type of finding is that attentional resources are allocated to the central feature of the threatening event (e.g., a gun) and reduced resources consequently remain to encode surrounding information.

From the above studies, we can infer that differential distribution of attention at the time of stimulus processing promotes memory for central details of emotional events but impairs processing of peripheral details. The hypothesis concerning different focusing patterns asserts that subjects visually fixate on different aspects of emotional versus neutral events. For example, the effects obtained in the Christianson and Loftus (1991) study might result from between-conditions differences in the number and duration of eye fixations expended on the central and the peripheral details. As for the central detail, the subjects in the emotional condition might have fixated more often on the central woman, whereas subjects in the neutral condition may have fixated more often on other aspects of the scene. Given that the accuracy of memory is related to the number of eye fixations (see, e.g., G. R. Loftus, 1972), such eye-fixation differences could account for why the central detail was better remembered in the emotional condition than in the neutral condition.

In the present study, we assume that the direction of attention is coordinated with fixation location. Using peripheral cues to direct attention away from fixation, Posner (1980) showed that attention and fixation location can, under some circumstances, be dissociated. However, Posner, Cohen, Choate, Hockey, and Maylor $(1984$, p. 51$)$ note that "in real world situations attention usually reorients to the fovea with each eye movement, thus keeping coordinated the center of acute vision with the direction of attention." In the present study (see Experiments 1 and 2) the cue is always in the same spatial location as the fixation, namely, on the central object. In line with Posner's work (Posner, 1980; Posner et al., 1984), these cues are expected to direct attention towards fixation, keeping the two coordinated.

Thus, to more closely evaluate focusing patterns and thus indirectly evaluate the role of attention in memory for emotional versus neutral events, a series of experiments was conducted in which subjects were presented with an emotional or a neutral event and in which the number of eye fixations was either controlled by using brief exposure times (Experi- ments 1 and 2) or monitored by tracking subjects' eye movements during the stimulus presentation (Experiment 3).

\section{Experiment 1}

In Experiment 1 , subjects were presented with basically the same stimulus material that was used by Christianson and Loftus (1991). In addition to the emotional and the neutral versions of the slides described earlier, an unusual condition was included. The unusual version showed an eye-catching event that was not particularly emotional: The woman is seen walking in the middle of a street carrying her bike on her shoulder. The unusual condition was included to determine whether an unusual event is remembered similarly to an emotional event, that is, if emotion affects memory for reasons that go beyond the unusualness or the distinctiveness of an emotional situation (cf. Christianson \& Loftus, 1991).

In Experiment 1, only one fixation per slide was allowed. This was accomplished by presenting the slides for $180 \mathrm{~ms}$ per slide and by having each slide preceded by a fixation point that was directed to a critical detail to be tested subsequently. Thus, for the critical slide in the emotional, the neutral, and the unusual conditions, the fixation point was directed to a detail associated with the central woman (the woman's coat), which was the same in all three conditions. This procedure assured that all subjects at the time of encoding paid attention to the same critical information and for the same amount of time.

If memory differences are found even when subjects have been equated with respect to number and location of eye fixations, then there is indirect evidence that differential distribution of attention at the time of presentation is not the only reason for the greater memorability of central detail information of emotional events.

\section{Method}

Subjects. The subjects were 134 University of Washington undergraduates. They were tested in groups of 5-10 subjects and received course credit for their participation. A total of 45 subjects, 44 subjects, and 45 subjects were tested in the emotional, the neutral, and the unusual conditions, respectively.

Apparatus. Slide presentation was carried out by means of two Kodak Carousel slide projectors. One had a self-timer and was used to project a fixation point. The second, which was used to project the stimuli, was equipped with a Gerbrands tachistiscopic shutter that allowed millisecond control of exposure times.

Materials. The stimulus materials consisted of one series of seven color slides. There were three versions of the critical slide. In the emotional version, the critical, fourth slide depicted a woman lying wounded (bleeding from a head injury) on the ground near her bicycle in front of a car. In the neutral version, the critical, fourth slide depicted the same scenic detail information as the emotional version, except that the woman was seen riding her bicycle near the same car. In the unusual condition, the critical, fourth slide depicted the same woman at the same spot in the street, but now she was walking in front of the car and carrying the bicycle on her shoulder. In all three conditions, a peripheral car was seen driving in the opposite direction in the distant background. The woman and the peripheral car were seen only in the critical slide. Slides 1-3 and 5-7 
in the series were identical in the three conditions and made equal sense for the neutral and the emotional versions. (For a more detailed description of the stimulus slides used in this experiment, see Christianson \& Loftus, 1991).

In addition, there was a series of fixation point slides; one fixation point slide preceded each stimulus slide. The fixation points were directed to a central detail of each of the seven picture slides.

Procedure. The slides were projected onto a screen $3-5 \mathrm{~m}$ in front of the subjects, resulting in an image size of $2.0 \mathrm{~cm}$ in diameter for the fixation points and $130 \mathrm{~cm} \times 90 \mathrm{~cm}$ for the stimulus slides. The fixation points were presented for $4 \mathrm{~s}$ each and remained directed to the critical detail information throughout the presentation of the picture slides, which were exposed for $180 \mathrm{~ms}$ per slide. There was a 2-s interval between each fixation point-picture slide pair.

For the critical, fourth slide in the emotional, the neutral, and the unusual conditions, respectively, the fixation point was directed to a detail associated with the central woman (the woman's coat), which appeared the same in the three conditions. Restricting the exposure time of the stimulus slides was intended to limit the number of eye fixations to just one per slide. This procedure assured that at the time of presentation, all subjects paid attention to the same critical information in the slides for the same amount of time.

Before the presentation of the slide series, the lights were dimmed, and a sample fixation point and a sample stimulus slide were shown. The subjects were instructed to look directly at the fixation point and continue to fixate on it throughout the very brief presentation of the picture slide. After it was determined that all subjects fully understood the instruction, the seven fixation point-picture slide pairs were presented.

Immediately after the presentation of the series of fixation pointpicture pairs, a 5-min filler task was inserted. In this filler task the subjects were handed a sheet showing twenty different geometric shapes, and a blank sheet on which the subjects were instructed to draw a picture of each of the geometric shapes.

After the filler task, subjects took a cued-recall test of the critical, fourth picture in the series of seven pictures. They were presented with the critical, fourth slide, but with the portion of it that depicted the woman, the bicycle, and the distant car obscured by a darkened field. The subjects were reminded that they had seen a woman lying next to a bicycle (emotional condition), riding a bicycle (neutral condition), or carrying a bicycle (unusual condition), in the darkened field of the slide, and then asked: "What color was the woman's coat?" A second question was: "What color was the car in the far background?" and the experimenter pointed out where the car was positioned in the darkened field. The subjects were allowed $45 \mathrm{~s}$ to write each answer. The subjects were also given a warning to make sure to write down an answer when there were $10 \mathrm{~s}$ left.

Next, the subjects were given a four-alternative-forced-choice recognition test of the critical, fourth slide in the relevant condition. One of the four simultaneously presented alternatives of the recognition slide had been shown in the study phase, and the remaining three alternatives-serving as distractors-were pictures that depicted the same event but varied with respect to either the central detail (woman's coat), the peripheral detail (car in the background), or both the central and peripheral details. For example, if the critical, fourth slide in the emotional condition depicted the wounded woman dressed in a blue coat and with a white Volvo in the background, the other alternatives in the test slide would show (a) the same woman dressed in a beige coat and with a white Volvo in the background, (b) the woman dressed in a blue coat and with an orange Volvo, and (c) the woman dressed in a beige coat and with an orange Volvo. The recognition slide (including the above four pictures) was exposed for $45 \mathrm{~s}$ in which subjects were to choose the precise alternative that they remembered seeing in the original slide sequence. The response was made by marking an $\mathrm{X}$ in the corresponding box on an answer sheet.
A sample recognition test slide was presented before testing the critical slide.

\section{Results}

The memory data from this experiment are reported separately for the recall test and for the recognition test. We first present the percentages of subjects who correctly recalled the color of the woman's coat (henceforth defined as central information), and the color of the car driving in the background (henceforth defined as peripheral information) in the critical, fourth slide (see Figure 1). Inspection of this graph suggests that the central information was better recalled in the emotional condition than in the neutral and the unusual conditions, while the peripheral information was slightly better recalled in the neutral condition than in the other two conditions.

Chi-square analyses conducted on the recall data for the central information revealed a significant difference between the emotional and the unusual group, $\chi^{2}(1)=4.46, p<.05$, and a marginally significant difference between the emotional and the neutral groups, $\chi^{2}(1)=3.24, p<.10$. Chi-square comparisons conducted on the percentages for the peripheral detail revealed that differences between groups were not significant.

The recognition data are presented in Figure 2. The percentages of subjects who correctly recognized both the central and the peripheral details were nearly equivalent for the three conditions (chance performance was $25 \%$ ). As in the recall data, the percentages of subjects who recognized only the central detail showed somewhat higher performance for the emotional group than for the other two groups (chance performance was $50 \%$ ). The emotional group showed, on the other hand, somewhat lower performance for the peripheral detail than did the other two groups. Chi-square analyses conducted on these percentages revealed a significant difference between the emotional and the unusual groups in recognition of the central detail, $\chi^{2}(1)=4.11, p<.01$. No other statistically significant differences were found between groups.

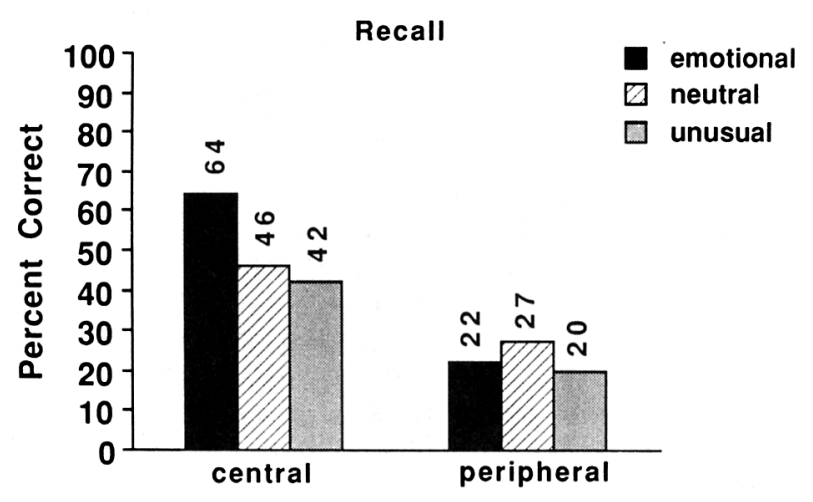

Figure 1. Percentages of subjects in the three conditions in Experiment 1 who correctly recalled the central or the peripheral detail information of the critical picture in the three conditions. 


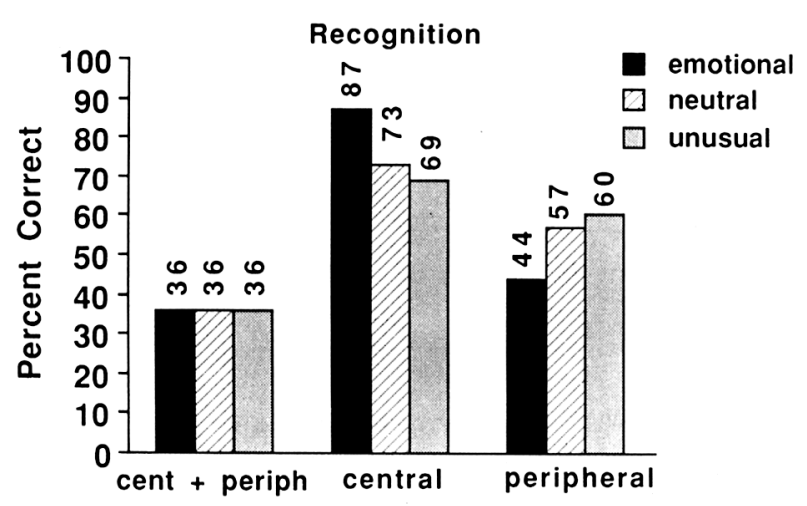

Figure 2. Percentages of subjects in Experiment 1 who correctly recognized both the central and the peripheral detail information of the critical picture or who recognized either the central or the peripheral detail information of the critical picture in the three conditions.

\section{Discussion}

The main finding from this experiment was the better recall performance for the central detail in the emotional event. This result is also congruent with earlier findings obtained by Christianson and Loftus (1991) using longer exposure times. Thus, despite the fact that subjects in the emotional, the neutral, and the unusual conditions were equated with respect to the detail information attended to during the stimulus presentation (i.e., the number of fixations was limited to one), memory of the central detail information of the emotional condition was better.

To test the generality of the results in Experiment 1, we conducted Experiment 2 with exactly the same procedure as in Experiment 1, but with different stimulus materials.

\section{Experiment 2}

In Experiment 2, two series of color slides were used for two versions of a story: one neutral and one emotional. A critical slide in each condition was presented for $150 \mathrm{~ms}$ per slide and preceded by a fixation point that was directed to either a boy walking beside a white car (neutral condition) or the same boy lying injured over the hood of the same white car (emotional condition). Subjects in the two conditions were then compared for memory of the color of the car.

\section{Method}

Subjects. One hundred and five University of Washington students who had not participated in Experiment 1 were tested under conditions similar to those in Experiment 1. Totals of 55 and 50 subjects were randomly assigned to the emotional and neutral conditions, respectively. Subjects were run in groups of 3 to 8 .

Apparatus, material, and procedure. The apparatus and the fixation point-attention-directing technique were similar to those used in Experiment 1 . The stimulus material was, however, different. In this experiment, two series of color slides (nine pictures in each) were used for two versions of a story: one neutral and one emotional. The neutral version showed in the first of three phases a mother and her young son leaving a house and walking to the downtown area of a city (three slides). The first slide of the second phase showed the son walking beside the right fender of a white car. The second two slides in the second phase showed the mother and son entering a cab and arriving at school. The third phase showed the mother alone, making a phone call, and then walking home (three slides).

The emotional version of the story was identical to the neutral version with respect to Phase 1 and Phase 3 . Phase 2 was, however, different. The first slide in this second phase of the emotional version showed the boy lying over the hood and the right front fender of the same white car. One of his eyeballs was hanging out and he was bleeding heavily from his injury. The second two slides in this middle phase showed the boy being treated in an emergency room and then heavily bandaged in a hospital bed with his mother at his side. (A more detailed description of the emotional and the neutral versions of the story can be found in Christianson, 1984).

In addition, fixation point slides were constructed in which the fixation points were directed to a central part of each of the nine picture slides in each version.

The procedure was similar to that of Experiment 1. The fixation points and the stimulus pictures were projected on a screen that was 3-5 $\mathrm{m}$ in front of the subjects. Each picture slide was preceded by a fixation point that was presented for $5 \mathrm{~s}$ and then remained throughout the succeeding picture slide, which was presented for $150 \mathrm{~ms}$. The subjects were instructed to look directly at the fixation point and to continue to fixate it throughout the very brief presentation of the picture slide. The experiment started with a sample pair of a fixation point slide and a picture slide and then continued with the presentation of either the emotional or the neutral version of the slide series.

Immediately after the slide presentation, a 5-min filler task was inserted, which involved the same geometric figure-copying task as was used in Experiment 1.

After the filler task, the subjects were asked to recall the color of the car that the boy walked beside in the neutral version, or, alternatively, the color of the car that hit the boy in the emotional version. Subjects were allowed $30 \mathrm{~s}$ to write down their response. The subjects were given a warning to make sure to write down an answer when there were $10 \mathrm{~s}$ left.

They were then given a six-alternative-forced-choice color recognition test of the same car that was asked about in the recall test. The colors yellow, red, green, blue, white, and black were written on a form, and the subjects were asked to mark the color that corresponded to the color of the car that was asked about in the recall test. Subjects were allowed $45 \mathrm{~s}$ for responding.

\section{Results and Discussion}

The percentages of subjects who correctly recalled the color of the car showed that the subjects in the emotional condition recalled the central detail more often $(80 \%)$ than subjects in the neutral condition (54\%). A chi-square analysis revealed a significant difference between groups, $\chi^{2}(1)=8.09, p<.01$.

The percentages of subjects who correctly recognized the color of the car in the critical, fourth slide were $82 \%$ and $56 \%$ for the emotional and the neutral conditions, respectively. These values show the same pattern of results that was found in the color-recall test. A chi-square analysis performed on these recognition percentages revealed a significant difference between the emotional and the neutral groups, $\chi^{2}(1)=8.24$, $p<.01$. The recognition performance is surprisingly close to recall performance. It may be that the subjects generated the same six colors used in recognition during attempts at recall, simply because these colors pretty much define the set of potential colors for cars.

Thus, subjects in the emotional condition remembered the detail information associated with the central part of the 
picture better than subjects in the neutral condition. This finding is congruent with the results of previous studies (e.g., Christianson, 1984; Christianson \& Loftus, 1987, 1991) and indicates that attentional distribution alone cannot explain the difference in memory for emotional and neutral events.

\section{Experiment 3}

Restricting people to just one eye fixation and to direct their attention with a fixation point, as we did in the previous two experiments, is rather artificial. So, in Experiment 3 we let the subjects fixate normally and recorded their eye movements during the stimulus presentation. This procedure allows us to determine whether the pattern of results obtained with only one eye fixation on the central detail also holds when the number of eye fixations is not restricted. To make our logic more explicit, consider the stimulus pictures used in Experiment 1 . If someone freely fixates three times on the central woman in the emotional condition, will that person remember the color of the coat better than a person with three fixations on the central woman in the neutral condition? To answer this question, we conducted Experiment 3 using an eye movement recording device. Subjects watched an extended version of the Experiment 1 stimulus pictures while their eye movements were monitored.

\section{Method}

Subjects. The subjects were 207 University of Washington students. The eye-tracking device required the creation of a wax impression of the subjects' teeth, which could be attached to the device to reduce head movements. In addition, a beam of light was reflected off of the surface of the subject's eye, requiring uncorrected normal vision. Forty subjects were dismissed because of vision or dental problems (e.g., contacts, glasses, or braces), or because of difficulties in recording their eye fixations (e.g., excessive head motion). After these subjects were discarded, a total of 56,54 , and 53 subjects were tested individually in the emotional, the neutral, and the unusual conditions, respectively.

Materials. The stimulus material constituted an extended version of the series of slides that was used in Experiment 1, but with the same critical picture that depicted the woman, the bicycle, and the distant car for the three conditions. The present series was composed of the same 15 slides that were used in a previous study by Christianson and Loftus (1991).

Eye-movement recording. The subject's eye movements were recorded during the study phase by using a modified Mackworth stand camera. This camera utilized a corneal reflection technique, and the output to a visual recording device consisted of (a) the same visual scene being viewed by the subjects and (b) superimposed on this scene, a spot of light (fixation spot), whose location corresponded to the area on the scene that the subject was fixating (accurate to within about $0.5^{\circ}$ of visual angle). The recording device was a closed-circuit television camera and a Hitachi VHS Camcorder video recorder. During the time in which the subject's eye movements were recorded, the scene and the fixation spot were visible to the experimenter by means of a TV monitor and were simultaneously recorded on videotape. A forehead rest and a bitebar were used to prevent head movements during the stimulus presentation. (See Loftus, 1972, for a more detailed description of the eye-movement recording device used in this experiment.)

Procedure. Each subject was randomly assigned to the emotional, the neutral, or the unusual condition. The slides were projected onto a screen $62 \mathrm{~cm}$ in front of the subject, resulting in an image size of $17 \times 11.5 \mathrm{~cm}$ for each slide.

Before the presentation of the 15 stimulus slides, the lights were dimmed, and a calibration slide was shown. Once the subject was properly aligned, he or she was instructed to pay close attention to the slide sequence depicting everyday scenes that a person might see on his or her way to or from work. The subject was informed that it was extremely important to keep his or her head as still as possible for the short time needed to show the slides. The slides were presented at a rate of $2.70 \mathrm{~s}$ per slide with a $4-\mathrm{s}$ interslide interval. Between slides a fixation point slide projected a dot onto the middle of the screen, which the subject was instructed to fixate. This fixation point slide made it possible to make fine adjustments to ensure that eye movements were accurately recorded.

Immediately after the presentation of the slide sequence, the subject was released from the head stand, and a 5-min filler task was inserted. This filler task was the same geometric figure task used in Experiments 1 and 2.

After the filler task, subjects took a recall test of the critical, 8th picture in the series of 15 pictures. The test slide was identical to the critical, 8th slide shown in the study phase, except that the woman and the distant car were missing. (A picture had been taken in which these two objects were excluded from exactly the same scene.) The subject was asked: "What color was the woman's coat?" and "What color was the car in the far background?" For each question, the subject was allowed $45 \mathrm{~s}$ to write down an answer and was given a time warning when $10 \mathrm{~s}$ remained.

Next, the subjects were given the same four-alternative-forcedchoice recognition test of the critical, 8 th slide. The recognition slide (including the above four pictures) was exposed for $45 \mathrm{~s}$ in which subjects were to choose the precise alternative that they remembered seeing in the original slide sequence. The response was made by marking an $\mathrm{X}$ in the corresponding box on an answer sheet. A sample recognition test slide was presented before the testing of the critical slide.

Eye-movement scoring. To analyze the eye-movement data, we played back the videotape at approximately one-tenth normal speed. The technique of slowing down the tape meant that the error in determining the number, position, and duration of eye fixations could be kept reasonably small. This determination was accomplished by means of a computer with an internal clock. Raters held down one of two buttons, according to the location of the fixation (one button for central and one for noncentral fixations). Hitting a button ended the timing of the previous fixation. Measurement of the final fixation was terminated by pressing a special button at the end of the slide. The computer then adjusted all fixation durations so that their sum totaled $2.7 \mathrm{~s}$ (i.e., the durations were transformed back to real time). Raters were blind to the subjects' memory performance.

\section{Results}

The mean percentage correct recall of the central detail and the peripheral detail are shown in Figure 3. Inspection of this graph shows that the subjects in the emotional condition recalled the central detail more often than did the other two groups, while no difference between groups can be seen for the peripheral detail. Two overall chi-square analyses conducted on these sets of data revealed a significant difference between groups for the central detail, $\chi^{2}(2)=12.62, p<.01$, and a nonsignificant difference for the peripheral detail, $p>$ .10. Separate chi-square tests between groups revealed a significant difference between the emotional and the neutral groups, $\chi^{2}(1)+9.17, p<.01$, and the emotional and the unusual groups, $\chi^{2}(1)=8.75, p<.01$. 


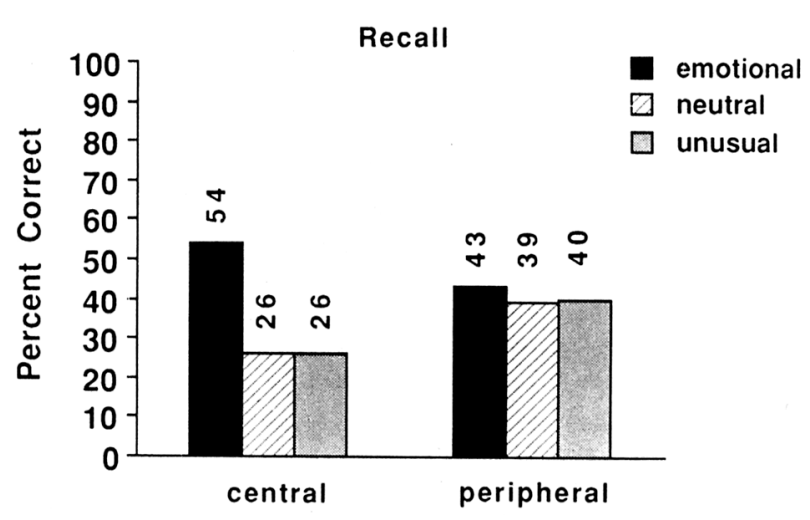

Figure 3. Percentages of subjects in Experiment 3 who correctly recalled the central and peripheral detail information of the critical picture in the three conditions.

The same basic pattern was obtained when the central and the peripheral detail were tested for recognition. The mean percentage correct recognition for the central detail-93\%, $59 \%$, and $58 \%$, for the emotional, the neutral, and the unusual groups, respectively - showed a significant difference between groups, $\chi^{2}(2)=19.58, p<.001$. There was a significant difference between the emotional and the neutral groups, $\chi^{2}(1)=17.19, p<.001$, and the emotional and the unusual groups, $\chi^{2}(1)=16.25, p<.001$. The mean values for the peripheral detail-57\%, 54\%, and $47 \%$, for the emotional, the neutral, and the unusual groups, respectively-showed a nonsignificant difference between groups, $p>.10$.

The eye-movement data were scored both with respect to number and duration of eye fixations. The mean duration of eye fixations made by the subjects in the three conditions is presented in Figure 4. This graph shows a significant difference between groups in mean duration of eye fixation on the central detail, $F(2,162)=3.50, p<.05, M S_{\mathrm{e}}=66,221$. The mean duration of eye fixations on other details also showed a significant difference between groups, $F(2,162)=3.73, p<$ $.05, M S_{\mathrm{e}}=58,972$.

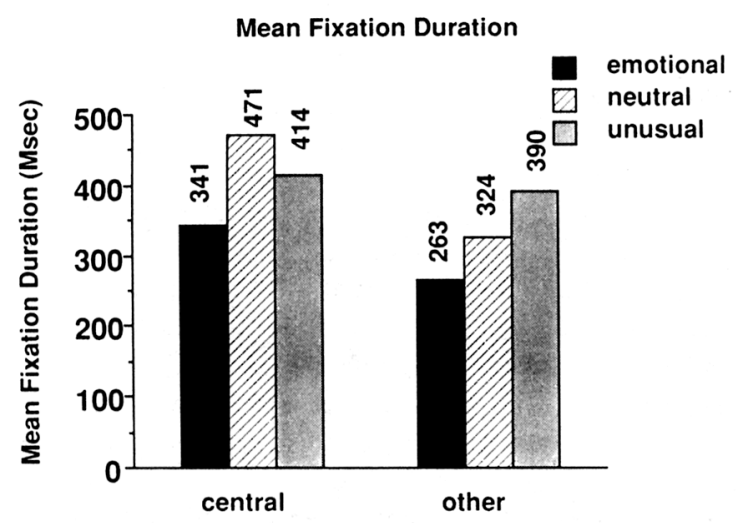

Figure 4. Mean number of fixation durations for the subjects in Experiment 3 on central and on other detail information in the three conditions.
The mean number of eye fixations made by the subjects in the three conditions is presented in Figure 5. There is a significant difference between groups in number of eye fixations on the central detail, $F(2,162)=35,00, p<.001, M S_{\text {e }}$ $=2.92$. Subjects in the emotional group fixated significantly more times on the central detail than subjects in either the neutral group, $t(108)=7.36, p<.001, S E=.33$, or the unusual group, $t(107)=6.76, p<.001, S E=.34$. With respect to number of eye fixations on any other detail, also shown in Figure 5, the pattern was just the opposite. There was a significant difference between groups, $F(2,162)=9.81$, $p<.001, M S_{\mathrm{e}}=4.10$, resulting from a lower number of eye fixations for the emotional group. Collapsed over central and other details, there was basically an equal number of eye fixations made by the subjects in the three conditions.

Taken together, subjects in the emotional condition fixated more often on the central detail than did subjects in the other two conditions, but they fixated on this detail for shorter durations. These results are consistent with previous research on eye movements and memory (see, e.g., Loftus, 1972), which has shown that number of eye fixations predicts memory performance, whereas fixation duration does not.

Figure 6 presents the distributions of number of centralobject eye fixations in the three conditions. It was common for subjects in the emotional condition to fixate three, four, five, or six times on the central woman. Also, it was common for subjects in the neutral and the unusual conditions to fixate three times on the central woman, although many subjects fixated four or five times. Somewhat fewer subjects fixated three and six times. Thus, it is only for three, four, five, and six eye fixations that we have a reasonable number of subjects in the three groups to compare with respect to memory accuracy. There were too few subjects for statistical analyses of the other numbers of eye fixations to be conducted.

Values for recall of the color of the woman's coat among subjects who made three, four, five, or six eye fixations on the woman, are presented in Figure 7. This graph indicates that when subjects made three, four, or five fixations on the central object, those in the emotional condition recalled the central detail better than subjects in the neutral or unusual conditions. However, when subjects made six eye fixations on the central object, a different pattern of results was obtained. In particular, the neutral subjects performed best. We cannot make much of this different pattern because there were so few subjects (only 3 ) in the neutral condition who made six fixations. For purposes of analysis, we collapsed over three to six eye fixations and performed a chi-square analysis, which revealed a significant difference between groups, $\chi^{2}(2)=9.16, p<.01$. Separate comparisons revealed a significant difference between the emotional and the neutral groups, $\chi^{2}(1)=6.50, p<.01$, and between the emotional and the unusual groups, $\chi^{2}(1)=6.51, p<.01$.

The percentages of subjects who correctly recognized the central detail (chance level was 50\%) are presented in Figure 8. This graph shows that when subjects made four, five, or six fixations on the central object, those in the emotional and neutral groups recognized the central detail better than subjects in the unusual group. However, when subjects made three fixations on the central object, a somewhat different 


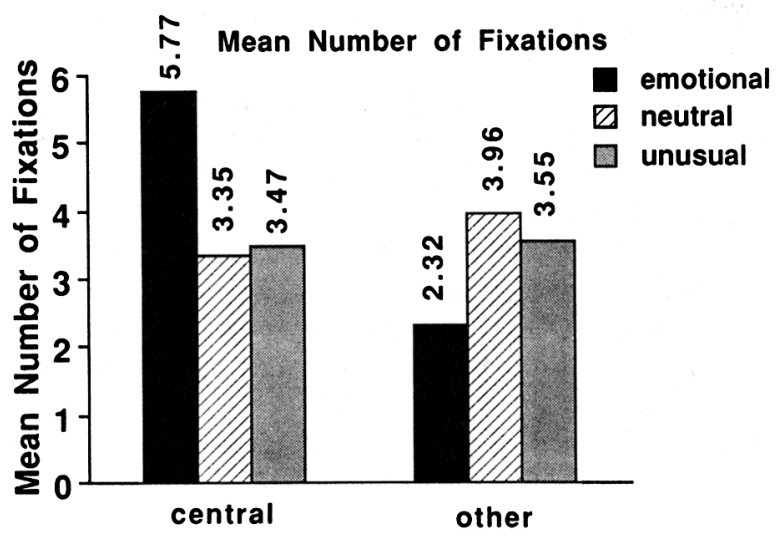

Figure 5. Mean number of eye fixations made by the subjects in Experiment 3 on central and on other detail information in the three conditions.

pattern of results was obtained. In particular, the neutral group performed the worst. We collapsed across eye fixations and found that the overall recognition performance was $88 \%$ for the emotional group, $69 \%$ for the neutral group, and $54 \%$ for the unusual group. An overall chi-square analysis performed on these percentages revealed a significant difference between groups, $\chi^{2}(2)=9.57, p<.01$. Separate chi-square tests between groups revealed a significant difference between the emotional and the unusual groups, $\chi^{2}(1)=9.66, p<.01$, and a near-significant difference between the emotional and the neutral groups, $\chi^{2}(1)=3.75, p<.06$.

One other aspect of the results is worth mentioning. Subjects who devoted, say, five fixations to the central detail did not have higher memory scores than subjects who devoted only three fixations. This seems contrary to other results (e.g., Loftus, 1972) wherein more eye fixations on a picture were associated with better memory for that picture. A probable reason for this discrepancy is as follows: In the Loftus (1972) study, several observations per condition per subject were collected, so the same subjects contributed to different number-of-fixations conditions. In the present study, only one

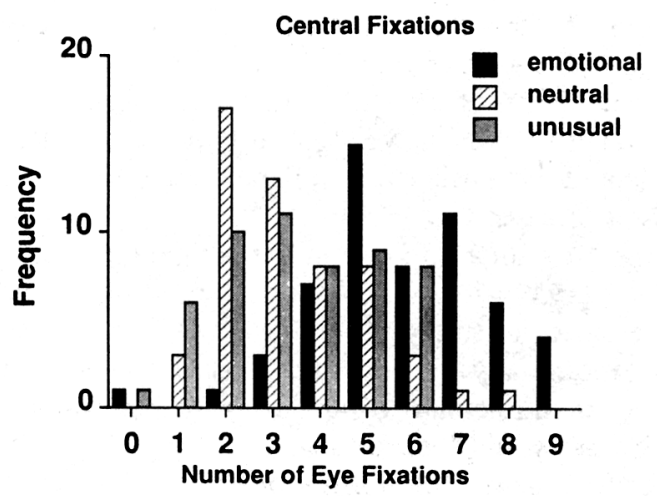

Figure 6. Distribution of eye fixations and number of subjects in the three conditions who made between zero and nine eye fixations on the central detail information in the three conditions (Experiment 3). datum per subject was collected, so different subjects contributed to different number-of-fixations conditions. Accordingly, any intrinsic performance differences across numbers of fixations in the present study may be obscured by subject selection effects. (For example, a subject may fixate a sufficient number of times to acquire a constant, criterion amount of information; the number of fixations required to achieve this criterion may differ from subject to subject.) In short, in Loftus (1972) subject selection effects were not an issue, where in the present analysis they could have contributed to the pattern of results.

The pattern of results from this third experiment is congruent with the results obtained in Experiments 1 and 2 and further supports the interpretation that attentional factors matter but are not the most critical factor in explaining the superior memory for central detail information in emotional events versus neutral events.

\section{General Discussion}

What happens when people watch an upsetting event versus a neutral version of that event? Do they distribute their attention differently? Our data suggest that people attend to a central detail more in the case of the upsetting version. In Experiment 3, when subjects were free to fixate on anything they wished, they made more fixations on the central object when they watched the emotional event. Does this mean that attention entirely explains our finding that memory for the central object was better in the case of the emotional event? The answer is no. Although attention does matter and may provide a partial explanation, it is not the entire explanation, as evidenced by data gathered when attention was restricted. In Experiments 1 and 2 we restricted the number of eye fixations to just one and directed the subjects' attention in each condition to the same detail information. Both experiments revealed the same result: The central detail was better retained by subjects in the emotional condition.

We do find that, taken together, subjects in the emotional condition make more eye fixations, but this cannot explain it all because we found better memory for the central detail in the emotional condition, even when subjects were equated with respect to the number of eye fixations on that critical central detail. This finding casts doubts on the hypothesis that the only reason why central detail information was better retained in emotional events (cf. Christianson \& Loftus, 1991), is that subjects look at the critical object longer or focus more attention upon it.

A critical assumption made in the beginning of this article was that eye movements are treated as essentially an operational definition of attention; that is, where the eyes go, so goes attention. Criticisms of this assumption were addressed in the introductory section of this article. However, one may argue that even if no eye movements were executed, the different experimental conditions could have affected covert shifts of attention. In particular, covert shifts could have been less prevalent in the emotional condition, possibly because this condition triggered an increase in focal attention. The fact that we did not obtain any significant effects for peripheral details (see Experiments 1 and 3) speaks against such an argument. Thus, an exclusively attentional explanation would 


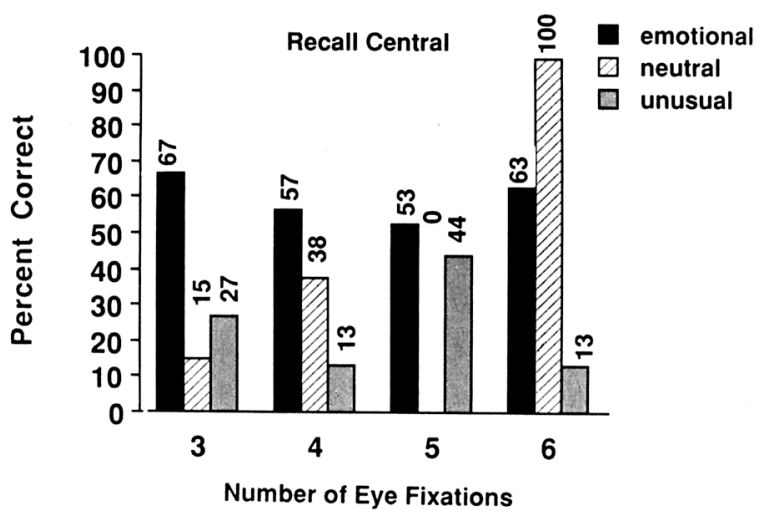

Figure 7. Percentages of subjects in Experiment 3 who correctly recalled the central detail information of the critical picture in the three conditions. (Values are given for subjects who made either three, four, five, or six eye fixations on the central detail information.)

predict a trade-off, but instead we got significantly enhanced memory for central details without a significant cost for peripheral details.

Why, then, is the central detail better remembered in the emotional condition? There are a number of possible explanations. One is that the emotional event is possibly more distinctive than the neutral event. For example, on the basis of G. R. Loftus and Mackworth's (1978) findings, it can be argued that the unusualness of emotional details or events is the critical factor that explains why emotional events are remembered differently than ordinary, neutral events. In the present study we included an unusual condition (Experiments 1 and 3), but the subjects in the unusual condition behaved in a similar manner to the subjects in the neutral condition. We acknowledge the possibility that the central information in the unusual condition was not as attention catching as the central information in the emotional condition. In fact, ratings made by subjects in a previous study using the same stimuli (see Christianson \& Loftus, 1991), indicated that the critical emotional slide was more attention catching than the critical unusual slide. On the other hand, ratings also revealed that the critical slide in the unusual condition was more

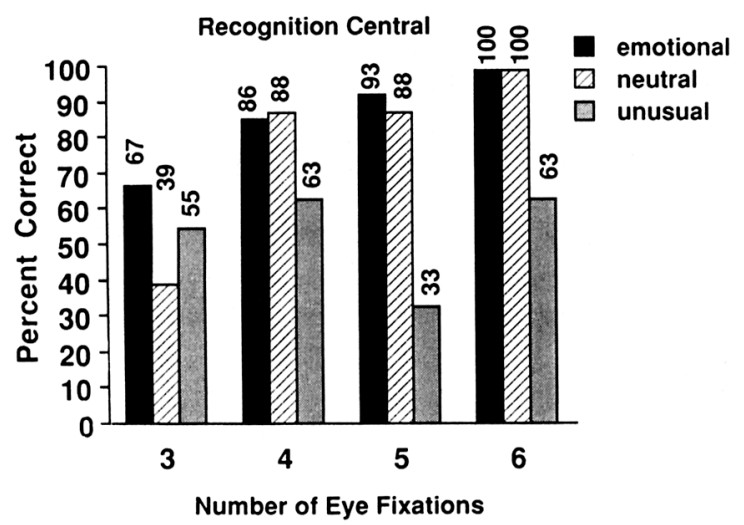

Figure 8. Percentages of subjects in Experiment 3 who correctly recognized the central detail information of the critical picture in the three conditions. (Values are given for subjects who made either three, four, five, or six eye fixations on the central detail information.) attention catching than the corresponding slide in the neutral condition, but without any accompanying differences between these conditions in memory for the central detail. Thus, it seems unlikely that the unusualness of emotional details fully explains why emotional details are remembered differently from ordinary, neutral ones.

Alternatively, there might be a special mechanism involved when we retain emotional events. This mechanism could affect memory at early perceptual processing or late conceptual processing. In the last section of this article we discuss, at a somewhat speculative level, hypotheses regarding such a special mechanism.

\section{Late Conceptual Processing}

Consider first factors at late conceptual processing. It may be that differential poststimulus elaboration occurs when subjects are exposed to emotional events as compared with neutral events (cf. Heuer, 1987; Heuer \& Reisberg, 1990; Rubin \& Kozin, 1984). An interesting discussion about elaboration on emotional thought content was provided by Heuer. Heuer argues that the recall pattern for emotional events and associated details is different from that of neutral events. For example, emotional memories center around the causes of the emotions-the thoughts, feelings, and reactions of the subject. One consequence is that the subject who is remembering is induced to personalize a narrative account around the central elements of the emotional experience.

Thus, subjects presented with emotion-provoking content, such as an accident, might be more concerned about what they have just seen-about the injuries of the victim, for example-which will lead to an increased poststimulus elaboration. Support for this hypothesis can be seen in a previous study in which the thoughts that were evoked in the subjects while they viewed a critical emotional or a neutral picture were gathered (Christianson \& Loftus, 1991). Analyses of these thoughts revealed that subjects' descriptions in the emotional condition were more likely to contain expressions of affect and were also more likely to make reference to the central character and the central action of the event. On the other hand, descriptions given by subjects in the neutral condition were more likely to make reference to the environment and various peripheral details and were less explicit about the central character of the event. These results, although far from conclusive, do hint that poststimulus elaboration could be critical to understanding how emotional events are processed.

The poststimulus elaboration hypothesis implies that Easterbrook's (1959) theory is supported in the sense that there is an increased cue selectivity and restriction of the attentional span in emotionally arousing situations. However, at the same time, the attentional narrowing during the processing of emotional events would then be associated with the more elaborative processing of the information attended to. Thus, when people are exposed to emotional events, fewer aspects of the total event are attended to, which enhances processing for central details but is detrimental to processing of peripheral or surrounding information of the emotional event (cf. Christianson, 1984; Christianson \& Loftus, 1987, 1991). 


\section{Early Perceptual Processing}

Many memory researchers are convinced that humans have different memory systems, which represent different stages in human development (see Tulving, 1987, for a review). Some observations in research on emotion and memory suggest that we retain emotional memories without a conscious recollection of how we acquired this information (see, e.g., Christianson \& Nilsson, 1989; Johnson, in press; Johnson, Kim, \& Risse, 1985; Tobias, Kihlstrom, \& Schacter, in press; Zajonc, 1980). It may be that this memory processing of the affective valence of experiences has a powerful influence on future processing of the specific event information (see LeDoux, in press). A more primitive memory mechanism may be engaged when we are confronted with emotionally arousing events. We may be preprogrammed to process emotional information in a special way that is inherent from earlier stages in human development. Thus, it is possible that emotional events are perceived by a mechanism that does not involve consciously controlled processes, and which, of course, interacts with phylogenetically and ontogenetically more sophisticated memory mechanisms (cf. implicit as opposed to explicit memory, see Graf \& Schacter, 1985; Schacter, 1987). The specific way in which emotional information might be processed by such a mechanism on one hand, and more consciously controlled mechanisms on the other, may be of importance for the differences seen between memory of emotional events and memory of ordinary, neutral events. It is, however, for future research to show which of the two broad classes of explanations-early perceptual processing or late conceptual processing-is most critical in explaining the type of findings presented here.

\section{References}

Christianson, S.-A. (1984). The relationship between induced emotional arousal and amnesia. Scandinavian Journal of Psychology, $25,147-160$.

Christianson, S.-A்., \& Loftus, E. F. (1987). Memory for traumatic events. Applied Cognitive Psychology, 1, 225-239.

Christianson, S.-Ä., \& Loftus, E. F. (1991). Remembering emotional events: The fate of detailed information. Emotion \& Cognition, 5, 81-108.

Christianson, S.-Ȧ., \& Nilsson, L.-G. (1989). Hysterical amnesia: A case of aversively motivated isolation of memory. In T. Archer \& L.-G. Nilsson (Eds.), Aversion, avoidance, and anxiety: Perspectives on aversively motivated behavior (pp. 289-310). Hillsdale, NJ: Erlbaum.

Easterbrook, J. A. (1959). The effect of emotion on cue utilization and the organization of behavior. Psychological Review, 66, 183201.

Graf, P., \& Schacter, D. L. (1985). Implicit and explicit memory for new associations in normal and amnesic subjects. Journal of Ex- perimental Psychology: Learning, Memory, and Cognition, 11, 501-518.

Heuer, F. (1987). Remembering detail: The role of emotion in longterm memory. Unpublished doctoral dissertation, New School for Social Research, New York.

Heuer, F., \& Reisberg, D. (1990). Vivid memories of emotional events: The accuracy of remembered minutiae. Memory \& Cognition, 18, 496-506.

Johnson, M. K. (in press). Emotion and MEM. In S.-A Christianson (Ed.), The handbook of emotion and memory. Hillsdale, NJ: Erlbaum.

Johnson, M. K., Kim, J. K., \& Risse, G. (1985). Do alcoholic Korsakoff's syndrome patients acquire affective reactions? Journal of Experimental Psychology: Learning, Memory, and Cognition, $11,22-36$.

Kramer, T. H., Buckhout, R., \& Eugenio, P. (1990). Weapon focus, arousal, and eyewitness memory: Attention must be paid. Law and Human Behavior, 14, 167-184.

LeDoux, J. E. (in press). Emotion as memory: Anatomical systems underlying indelible neural traces. In S.-A. Christianson (Ed.), The handbook of emotion and memory. Hillsdale, NJ: Erlbaum.

Loftus, E. F. (1979). Eyewitness testimony. Cambridge, MA: Harvard University Press.

Loftus, E. F., Loftus, G. R., \& Messo, J. (1987). Some facts about "Weapon Focus." Law and Human Behavior, 11, 55-62.

Loftus, G. R. (1972). Eye fixations and recognition memory for pictures. Cognitive Psychology, 3, 525-551.

Loftus, G. R., \& Mackworth, N. H. (1978). Cognitive determinants of fixation location during picture viewing. Journal of Experimental Psychology: Human Perception and Performance, 4, 565-572.

Maass, A., \& Kohnken, G. (1989). Eyewitness identification: Simulating the "weapon effect." Law and Human Behavior, 13, 397408 .

Posner, M. I. (1980). Orienting of attention. The VIIth Sir Frederic Bartlett Lecture. Quarterly Journal of Experimental Psychology, 32, 3-25.

Posner, M. I., Cohen, Y., Choate, L., Hockey, G. R. I., \& Maylor, E. (1984). Sustained concentration: Passive filtering or active orienting? In S. Kornblum \& J. Requin (Eds.), Preparatory states and processes (pp. 49-65). Hillsdale, NJ: Erlbaum.

Rubin, D. C., \& Kozin, M. (1984). Vivid memories. Cognition, 16, $1-15$.

Schacter, D. L. (1987). Implicit memory: History and current status. Journal of Experimental Psychology: Learning, Memory, and Cognition, 13, 501-518.

Tobias, B., Kihlstrom, J. F., \& Schacter, D. (in press). Emotion and implicit memory. In S.-A. Christianson (Ed.), The handbook of emotion and memory. Hillsdale, NJ: Erlbaum.

Tulving, E. (1987). Multiple memory systems and consciousness. Human Neurobiology, 6, 67-80.

Zajonc, R. B. (1980). Feeling and thinking: Preferences need no inferences. American Psychologist, 35, 151-175.

Received March 22, 1990

Revision received October 16, 1990

Accepted October 29, 1990 